\title{
Digital education prospects after COVID 19
}

\author{
Evgeniia Dragunova*, and Anna Sokolova \\ Novosibirsk State Technical University, Prospekt K. Marksa, 20, 630073 Novosibirsk, Russia
}

\begin{abstract}
The article describes the transformation of higher education during and after the pandemic. Digital Education is examined as one of the ways that can ensure the achievement of sustainable development goals. Not only positive features of digital education but also obstacles on the way to its development and implementation are considered. It's determined how much the scientific community is interested in the subject of digital education. There has been analyzed the sentiment of blogosphere visitors who create and discuss the content related to the topic of digital education. The analysis identifies that negative posts are associated with the topic of digital security and the risk of digital addictions. In addition, this article presents the results of Internet-based testing of students that reveal the level of digital literacy and readiness to work in a digital environment. The problems students face are mainly related to aspects such as "digital content creation skills" and "digital security". Also, the analysis of the frequency of interaction with gadgets and the risk of student digital addiction is carried out. It's revealed that some of the respondents have a risk of internet addiction and a high level of nomophobia.
\end{abstract}

\section{Introduction}

Universities are an essential component of the educational ecosystem. Their role in strengthening educational policies and practices at all levels (training scientists, business leaders, future politicians, etc., creating unique educational content and conducting educational research) is central to rethinking education to address COVID-19. Currently, universities face the difficult task of choosing the path of transformation: transform and become something fundamentally new, optimize their existing operations in search of further efficiency and increased opportunities, do nothing, hoping for help from the state, do nothing, considering they already have a prospective future.

The reality is that employers point out that they are looking for social skills, emotional intelligence, teamwork skills, communication and time management skills in their future employees, and they feel that universities do not pay enough attention to these competencies. By analogy with a real business, modern university cannot ignore the client experience, i.e. the student experience as a learner and a developing person. Previously student preferences in many ways were determined by limited resources, geographic boundaries and limited information, now these obstacles have almost ceased to exist. Universities face a choice - online education based on the idea of learning at a convenient

*Corresponding author: Dragunova@corp.nstu.ru 
time from a convenient location, individual "exclusive" offline learning (on campus) or a compromise between physical and virtual learning in the form of Augmented Reality Learning Environment. The fourth industrial revolution will be accompanied by changes in the preferred method for education and the "restructuring" of the institutions that will provide it. With the use of advanced digital tools (big-data, AR/VR/MR, AI/Machine learning, IoT), University 4.0 will allow tracking and processing student digital footprint in real-time. Product approach and collaborations with industrial partners, the scientific community, and the state will provide an opportunity to create flexible client-oriented educational programs and unique individual offers.

Conditions have become more severe during the pandemic, and universities need a considered and conscious complex transformation. Thinking through the scale of transformation, it is necessary to answer several serious questions, such as: what is the scale of our university? What kind of clients are we going to serve, and what are their client expectations? How do we understand what exactly our clients want? To what extent are we structurally and infrastructurally ready for the "force majeure"? What processes do we need to restart for a successful digital transformation? One of the important issues when carrying out digital transformation procedures of the university is the determination of the student readiness to work in a digital environment. This article is devoted to the consideration of various aspects of this issue.

\section{Materials and Method}

The methods used in this article: the tools of bibliometrics showing the dynamics of interest in this topic from the scientific community, sentiment analysis showing the sentiment of the blogosphere participants about the topic of digital education, Internet-based testing, allowing to conclude the level of student digital literacy and the risk of digital addiction, as well as statistical methods by which it is possible to identify the presence/absence of a relationship between different aspects of given concepts.

\section{Results and Discussion}

According to UNESCO, in April 2020, schools and universities were closed in 185 countries. This event affected more than one and a half million students (90\%) [1]. Digital education "is increasingly recognized as a means capable of ensuring the achievement of sustainable development goals, a tool for maintaining the creative and innovative potential of people around the world at the proper level" [2]. The implementation of digital technologies into the educational process makes it possible to simultaneously train a significant number of people, retrain and improve the qualification of companies' employees in the remote access mode, to "collect" a digital footprint and analyze the success and progress of the educational process. It also saves material costs through the implementation of virtual laboratories and reduces risks through the use of VR/AR simulators and trainers. Among the advantages of digital education, it should also be noted [5] individualization of education; expanding learning opportunities; development of the ability to analyze; increasing student self-motivation.

The European Commission has developed The Digital Education Action Plan (20212027), which presents its vision for high quality, inclusive and affordable digital education in Europe. The plan takes practices and gained experience from the educational process implementation during a pandemic into account. The new Plan identifies two strategic priorities: support of development of a highly efficient digital education ecosystem and Digital skills improving and digital transformation competencies [3]. The results of public 
consultations conducted to establish the plan from June to September 2020 showed that almost $60 \%$ of respondents did not use distance and online learning before the crisis; $95 \%$ believe the COVID-19 crisis had marked a point of no return in the way technology is used in learning.

Resources and content for online learning need to be more relevant, interactive and easier to use. Over $60 \%$ believe they improved their digital skills during the crisis, and over $50 \%$ of respondents want to develop them further.

\subsection{Digital education. Issues of digitalization and hybridization}

The International Association of Universities (IAU) study provides data showing the varying degree of universities' readiness to a complete switch to online educational programs. Nevertheless, realizing the strategic importance of online education even before the crisis, universities were not able to prepare a large percentage of fully-fledged online programs. Less than $2 \%$ of programs in physics, biology, history, geography, mathematics and less than $3 \%$ in engineering and science are available online. But there are also more successful examples such as economics (7\%), linguistics (10\%), business research (12\%) [4]. Additionally, U-Multirank data shows low availability of interactive learning tools and digital exams, suggesting that large-scale online support is still difficult for many universities.

We used the webofknowlege.com toolkit to understand how interesting the topic of digital education was to the scientific community over the past ten years. More than 47 thousand scientific articles have been indexed during this period, and this number increases annually (Fig. 1). A significant contribution to the study of the topic is made by the authors of the countries, shown in Figure 2. As promising areas related to digital education should be identified: research in education, computer science, electronics, information systems, engineering, medicine, management and social sciences, as well as the presence of interdisciplinary research, for example, at the intersection of education and computer science, medicine and education.

With the help of the sentiment analysis tools, we have explored what emotions the "Digital Education" topic evokes in blogosphere visitors. It was found out that, in general, most posts on social networks and messengers are either positive or neutral (45\% - positive posts; $52 \%$ - neutral; $3 \%$ - negative).

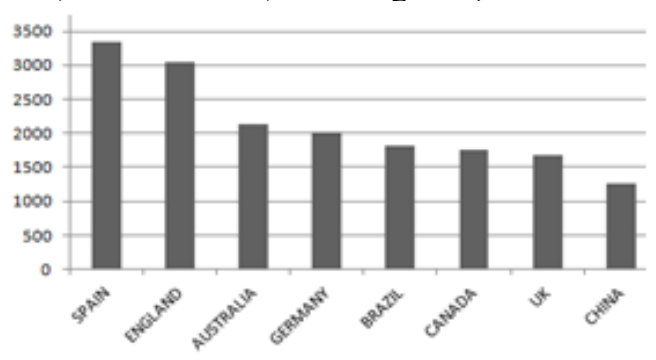

Fig. 1. Dynamics of indexed publications by keywords "Digital education" in the period 20102020 .

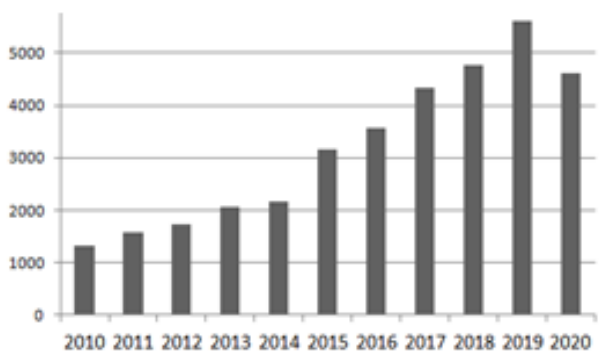

Fig. 2. Contribution of authors from different countries to the study of the «Digital education» topic.

Negative posts have been identified on Instagram and Reddit (7:3 ratio) and relate to digital security issues. The prevalence of positive and neutral colouration is confirmed by the tag-cloud, heat map and posts "mood" (Fig. 3). Over the course of several weeks, tracking topics united in clusters, we have noticed three main areas: University 4.0 (including the possibility of using artificial intelligence), discussion of gender issues such 
as the role/place of women in digital education, and issues of virtual reality and media in education.

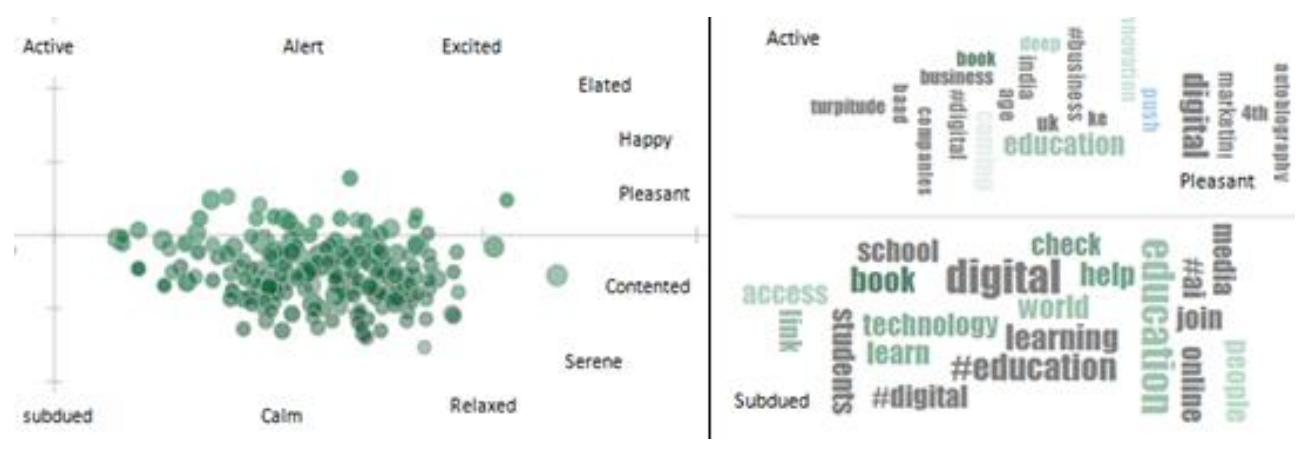

Fig. 3. Tag-cloud and visualization of messages' "sentiment" retrieved from Twitter using the keyword "Digital education".

In addition, heat maps were changing gradually, and tweets shifted from active towards passive and neutral in content. Negative tweets related to the discussion of barriers to digital education (Fig. 4) and the risk of addictions appeared.

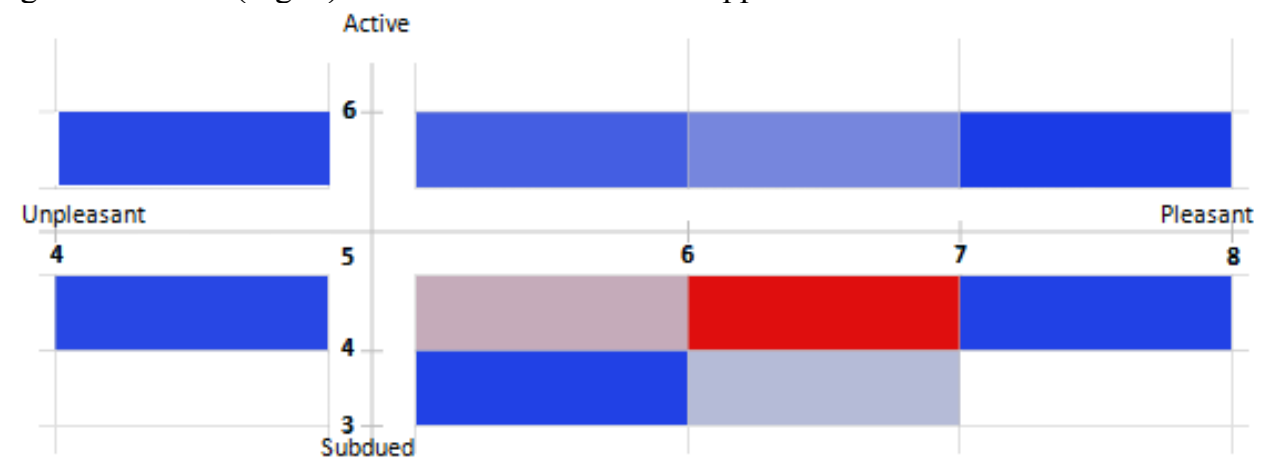

Fig. 4. Heat Maps of messages retrieved from Twitter using the keyword "Digital education".

The digital education concept is not only about positive characteristics. The obstacles to effective digital education are limited opportunities for students to access technologies outside the university (for example, in [6] this problem was noted by $42.5 \%$ of respondents), lack of time to master new technologies (ibid., 39.4\%), a small number of alternative MOOCs and digitized programs, with a large number of heterogeneous technologies and devices used in working with students, weak participation of external actors in the preparation and the expertise of training materials, limited digital learning standards and technological support, students' increasing addiction to gadgets, to social networks and messengers, limited statistics regarding the effectiveness of certain technologies and technological solutions in practice, etc. The obstacles to mass "migration" from traditional full-time education to online education are systematized here [7]. These include, for example, current IT infrastructure, education technical support level, teachers' digital literacy skills, internationalization programs, students from socially vulnerable families, student stress and mental health, additional financial costs of educational institutions, etc. [8-9].

After assessing the attitude towards digital technologies in the Russian Federation, it can be noted that more than half of the population (60\%) [10] consider themselves poorly informed about modern technologies, and $38 \%$ are worried about their impact on everyday 
life. The survey results of students from families with different income levels regarding the possibilities of inclusion in the digital (distance) learning mode are presented in the study [11]. The survey showed that only $40 \%$ of the respondents from low-income families answered that they get the necessary equipment for distance learning ( $72 \%$ high-income families) and 56\% have proper Internet access (77\% high-income families). Covid 19 has made its own adjustments to the mobility of international students. The study [1] notes that $39 \%$ of international students decided to interrupt their studies in international programs. International exchange programs were cancelled in several countries (43\%).

The OECD in its report [12] recommends to education and online collaboration policymakers to consider ways to balance between digital and "screen-free classes", options for tracking student emotional health, technological solutions that provide communication, interaction and support in the learning process (especially in uncertain times) and provide access to devices, including smartphones and laptops (the option of borrowing laptops or providing alternative resources (printed workbooks) (for example, GBR, JPN); manage IT infrastructure access and control its quality.

\subsection{Students' readiness for digital learning}

In April 2020, a survey of first-year students (112 people, undergraduates, economics programs) regarding associations related to the concept of "digital education" (Fig. 5) was conducted. Among the most popular answers, the leading ones are: stable, relevant, employable, affordable and continuous. There is not a single answer (keyword) in the constructed tag-cloud that has a negative connotation. The transition from offline to virtual learning leads to a modification of assessment methods learning outcomes, a revision of the skills and competencies required by students in this area [13]. Student readiness for online learning can be determined [14], for example, by three aspects: student preferences for the forms of education, student confidence in the effectiveness of electronic communication for learning (technical competencies) and their self-learning ability (including timemanagement). During the pandemic, the list of criteria has expanded due to technological equipment physical availability, the available learning experience with digital technologies, and the self-assessment skills of digital distance learning. Also, stress-related emotions, the desire of students to be part of the community, to participate in communications [15] played a role. At the same time, some studies show the developing social (physical) distancing and feeling of loneliness during the pandemic, called the global virus of loneliness or the epidemic of loneliness [16 - 17].

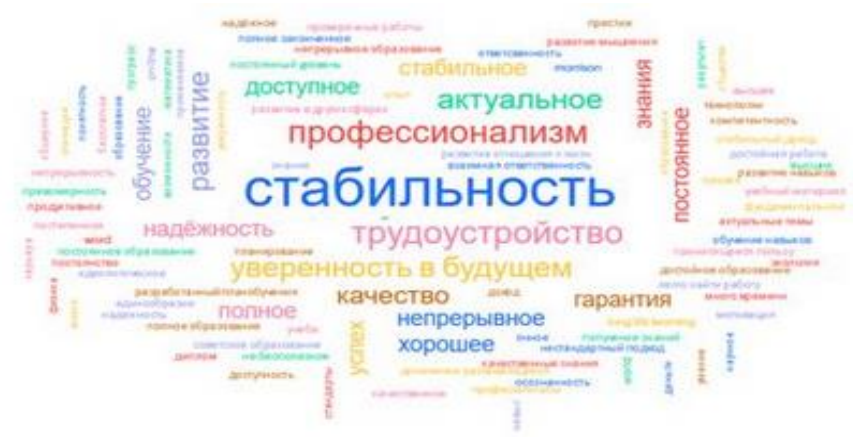

Fig. 5. Tag-cloud of "digital education" associations.

We found out how ready students are for digital interaction and whether there are significant gender differences. In the study (September 2020), we conducted online testing 
of digital literacy level (183 people) of first-year undergraduate students (economics programs): $43 \%$ men, $57 \%$ women. According to the test results, $46 \%$ of respondents are "advanced" (more than 70 points) on aspects of "digital content creation" and "digital security". Advanced level of "communication literacy" and "problem-solving skills in the digital environment" is observed in $65 \%$ and $66 \%$ of respondents respectively. From 1 to $3 \%$ of respondents have an elementary level in any of the aspects, the rest are basic. Compared to the results of the NAFI study conducted in 2020 [18], the students who participated in our testing have higher levels in all aspects. If the respondents who scored no more than 50 points in any of the aspects are considered separately, then "problematic" components become noticeable - digital security (13\% of respondents) and digital content creation skills (12\% of respondents). In the growing digitalization conditions of the main areas of activity, these students may have difficulties in ensuring the protection of personal data and the results of intellectual work, they will not always be able to present the results of their activities in media formats. Talking about the gender aspect, the smallest gap (less than $2 \%$ ) was found regarding digital content creation skills. On average, values in women are $7 \%$ lower than in men. As for the minimum values (Table 1), the difference between men and women is significant (35 - 45\%).

Table 1. Students' testing "Level of digital competencies: 4 aspects" results.

\begin{tabular}{|c|c|c|c|c|}
\hline \multirow{2}{*}{ Characteristics } & \multicolumn{4}{|c|}{ Aspect value } \\
\cline { 2 - 5 } & $\begin{array}{c}\text { Digital } \\
\text { content } \\
\text { creation } \\
\text { skills }\end{array}$ & $\begin{array}{c}\text { Digital } \\
\text { security }\end{array}$ & $\begin{array}{c}\text { Problem- } \\
\text { solving skills } \\
\text { in a digital } \\
\text { environment }\end{array}$ & $\begin{array}{c}\text { Ability to } \\
\text { communicate } \\
\text { in a digital } \\
\text { environment }\end{array}$ \\
\hline $\begin{array}{c}\text { Values according to the results of the } \\
\text { NAFI study [16] for the categories } \\
\text { student (not working/working) }\end{array}$ & $59 / 57$ & $61 / 68$ & $61 / 62$ & $64 / 65$ \\
\hline Average value (m/f) & $68.3 / 67$ & $69.4 / 66.1$ & $75.6 / 70.4$ & $75.2 / 69.6$ \\
\hline MAX (m/f) & $93 / 96$ & $100 / 93$ & $100 / 93$ & $100 / 96$ \\
\hline MIN (m/f) & $62 / 25$ & $80 / 33$ & $73 / 26$ & $79 / 36$ \\
\hline
\end{tabular}

The second phase of the study was to identify "dangerous" trends among first-year students regarding digital addiction (Internet addiction, nomophobia). We have interviewed 77 people. The results showed that the risk of Internet addiction is observed in $18 \%$, and strong nomophobia in $23 \%$ of respondents. The results of Internet-based digital literacy testing of students with a risk of digital addiction show that they have a level in the range from 65 to 71. Student gadgets screen time analysis (StayFree app for Android and Screen Time for IOS) showed that, on average, they spend from 6 to 10 hours a day on the Internet (6 hours 55 minutes on average around the world [19]), from 3 to 5 hours a day using streaming services (1 hour 34 minutes on average around the world [19]) and from 2 to 5 hours using social media ( 2 hours 29 minutes on average worldwide [19]). Tracking the number of "raises" showed that this group of students is characterized by 20 to 140 raises, while the next step after they raise their phone is usually an opening of the social network VK or Instagram.

The third stage of the study consisted of a students" "level of readiness for change" survey ( 77 respondents). The results show that $77 \%$ of students make decisions quickly, relying on themselves, they are ready for changes and will be able to try to find benefits from the problem situation. 


\section{Conclusions}

Education for sustainable development requires virtual mobility, digital literacy and student awareness of the educational goals, i.e. a high level of engagement in the learning process. Every student should have virtual access to educational resources without leaving the house, but this does not negate excursion programs, internships and trips abroad as part of university networking. Each student needs fundamental skills to work in a digital environment with the information presented in different formats. Digital literacy is aimed at continually searching, critically evaluating information, and producing your content to interact with other members. Students need communication, including inclusive virtual events. It is necessary to minimise the "developing during a pandemic social (physical) distancing and feelings of loneliness".

To meet these needs, it is necessary to provide an appropriate level of training for teachers. The educational ecosystem should ensure the implementation of the BYOD concept; readiness of higher education institutions for the rapid integration of various systems or the creation of new applications from different systems using APIs; the transition to cloud technologies and the creation of Hybrid Data Centers (local and cloud); development of its own massive open educational courses and access to the OER; equal access to technology for users with different types of disabilities.

In addition, an important aspect is the availability of student data analysis technologies to identify trends in student behaviour and factors affecting their loyalty to the educational institution, academic performance, personal growth, satisfaction with various services, etc.

\section{References}

1. The Impact of COVID-19 on Higher Education around the world (2020) https://iauaiu.net/

2. N. S. Ilyushenka, Designing the future. Problems of Digital Reality, 215 (2019) https://keldysh.ru/future/

3. Digital Education Action Plan (2021-2027). Resetting education and training for the digital age (2021) https://ec.europa.eu/

4. Regional/National Perspectives on the Impact of Higher Education (2020) https://www.iau-aiu.net

5. What Is The Digital Education System And Its Advantages For Students (2020) https://www.theasianschool.net/

6. Digital Learning: What to Know in 2020 (2020) https://www.schoology.com/

7. The Transformation of Higher Education After the COVID Disruption: Emerging Challenges in an Online Learning Scenario (2021) https://pubmed.ncbi.nlm.nih.gov/

8. E. V. Dragunova, N. V. Pustovalova, L. S. Dragunova, Science prospects, 8(119), 10 (2019)

9. E. V. Dragunova, N. V. Pustovalova, I. A. Valdman, Actual problems of electronic instrument engineering (APEIE-2018), 1(6). 358 (2018)

10. Bolee treti rossiyan opasayutsya razvitiya sovremennykh tekhnologiy (More than a third of Russians fear the development of modern technologies) (2020) https://nafi.ru/analytics/

11. COVID-19 and US higher education enrollment: Preparing leaders for fall (2020) https://www.mckinsey.com/ 
12. OECD. Education responses to covid-19: Embracing digital learning and online collaboration (2020) https://read.oecd-ilibrary.org/

13. Higher Education in the Digital Era: The Current State of Transformation Around the World. International Association of Universities (IAU) (2019) https://www.iau-aiu.net/

14. D.Warner, G.Christie, S. Choy, Readiness of VET Clients for Flexible Delivery Including On-line Learning ANTA, 64 (1988)

15. M. Händel, M. Stephan, M. Gläser-Zikuda, B.Kopp, S. Bedenlier, Al. Ziegler, Journal of Research on Technology in Education (2020)

16. Z. Newmark, We can stop loneliness while we stop coronavirus: Dutch King (2020)

17. P. Courtet, E. Olié, C. Debien, et al., J Clin Psychiatry. 81(3), 20com13370 (2020)

18. NAFI: digital literacy of Russians (2020) https://www.crn.ru/

19. Digital 2020 Global Overview Report (2020) https://wearesocial.com/ 